\title{
The Evaluative Effectiveness of a Combined Index Exceeded That of a Single Variable for the Ovarian Reserve and Response of Infertile Women
}

Shan-Jie Zhou ( $\sim$ zhoushanjie@126.com )

Peking University International Hospital https://orcid.org/0000-0002-6134-8671

Ming-Jia Zhao

Tangshan Maternity and Child Healthcare Hospital

Cui Li

Tangshan Maternity and Child Healthcare Hospital

Xing Su

Tangshan Maternity and Child Healthcare Hospital

Research article

Keywords: Anti-Müllerian hormone, Antral follicle count, FSH/LH ratio, Infertility, female, Ovarian response prediction index (ORPI), Reproductive hormone

Posted Date: December 17th, 2019

DOI: https://doi.org/10.21203/rs.2.18786/v1

License: (9) This work is licensed under a Creative Commons Attribution 4.0 International License. Read Full License 


\section{Abstract}

Background: Aim of the present study was to explore the evaluative effectiveness of age, ovarian volume, antral follicle count (AFC), serum follicle-stimulating hormone (FSH), anti-Müllerian hormone (AMH), $\mathrm{FSH} / \mathrm{LH}$ ratio and ovarian response prediction index (ORPI) to determine which could most advantageously assess ovarian reserve and response.

Methods: This research enrolled 319 consecutive infertile women who had undergone IVF-ET/ICSI treatments. Abovementioned variables were measured and calculated. Receiver Operating Characteristic Curve analysis was used to analyze the predictive accuracy of variables and to calculate cut-off values and corresponding sensitivity and specificity.

Results: Our study revealed that the significant variables for evaluating a decline in ovarian reserve include age, total volume of bilateral ovary, FSH, and ORPI. Moreover, the area under the curve (AUC) of ORPI was higher than other three variables (AUC $=0.903$ ), and the cut-off value of ORPI was 0.245 (sensitivity $90.1 \%$, specificity $73.9 \%$ ). The significant variables forecasting excessive ovarian response were age, $\mathrm{AFC}, \mathrm{AMH}, \mathrm{ORPI}, \mathrm{FSH}$ and $\mathrm{FSH} / \mathrm{LH}$ ratio, and the significant variables forecasting low ovarian response were $\mathrm{AMH}$ and $\mathrm{FSH} / \mathrm{LH}$ ratio. ORPI and $\mathrm{FSH} / \mathrm{LH}$ ratio presented better effectiveness in evaluating ovarian response. When they were used to predict excessive response, the cut-off values of ORPI and $\mathrm{FSH} / \mathrm{LH}$ ratio was 0.886 (sensitivity $84.7 \%$, specificity $67.3 \%$ ) and 1.753 (sensitivity $56.2 \%$, specificity $67.6 \%$ ), respectively. When used to predict low response, the cut-off value of FSH/LH ratio was 2.983 (sensitivity $75.0 \%$, specificity $83.8 \%$ ).

Conclusions: ORPI performed better than did the other variables in evaluating ovarian reserve and predicting excessive ovarian response, and the $\mathrm{FSH} / \mathrm{LH}$ ratio performed better than did the other variables in predicting low ovarian response. Consequently, we agreed that the evaluative effectiveness of a combined index exceeded that of a single variable for evaluating the ovarian reserve and response of infertile women.

\section{Introduction}

Several studies [1-4] have revealed that age, antral follicle count (AFC) and serum anti-Müllerian hormone (AMH) levels reflect the ovarian reserve admittedly, so these factors are considered valuable predictors of the ovarian response to exogenous gonadotrophins. In addition, AMH was a key for ovarian reserve-related outcomes, and has indeed been widely used in clinical practice. Sixty percent of the respondents from 796 infertility clinics worldwide reported using $\mathrm{AMH}$ as a first-line test in in vitro fertilization (IVF) cycles, and 54\% reported $\mathrm{AMH}$ as the best test for evaluating ovarian reserve; eightynine percent reported that $\mathrm{AMH}$ results were relevant to clinical practice [1]. And $\mathrm{AMH}$ was an effective measure of quantitative ovarian reserve and was strongly associated with the ovarian response and oocyte yield after ovarian stimulation [2, 3], moreover, using AMH, AFC and age together constituted the best model for predicting poor or excessive ovarian response [4]. 
However, several scholars have considered the evaluative effectiveness of the above parameters to be unsatisfactory and inaccurate for clinical practice. For example, Hvidman et al. [5] stated that serum AMH and AFC were not lower in infertile patients aged 20-39 years than in a control group of the same age with no history of infertility. Furthermore, debate exists regarding whether a single parameter or a combined index (follicle-stimulating hormone/luteinizing hormone ratio, FSH/LH ratio; ovarian response prediction index, ORPI) is a superior tool for evaluating the ovarian reserve or response. The FSH/LH ratio can be used to differentiate between decreased and normal response cycles, and the elevated day-3 $\mathrm{FSH} / \mathrm{LH}$ ratio is associated with an inferior outcome in IVF treatment cycles [68]. Oliveira et al. [9] innovatively used ORPI to assess ovarian response and found that ORPI exhibited an excellent ability to predict low or excessive ovarian response, a collection of greater than or equal to four MIl oocytes and the occurrence of pregnancy in infertile women.

We retrospectively enrolled 319 consecutive infertile women who had undergone IVF/intracytoplasmic sperm injection (ICSI) treatments from September 2016 to August 2017 and explored the effectiveness of the parameters to determine which could be used to most advantageously assess ovarian reserve and response.

\section{Materials And Methods}

Subjects and study groups

The study population consisted of 319 consecutive infertile women between the ages of 21 and 45 who had experienced infertility lasting 1-18 years, all subjects experienced at least 1 year without pregnancy success with natural attempts and were the first time to have IVF treatment, and administrated gonadotropin-releasing hormone $(\mathrm{GnRH})$ antagonist protocol to perform ovulation induction. Patient history and clinical information were obtained from their medical records. All of the women were determined to have both ovaries present, no history of ovarian surgery, no severe endometriosis and no evidence of endocrine disorders. Conventional IVF and/or ICSI were performed according to the cause of infertility. Infertile women were excluded if they were using fertility drugs (for example, clomiphene, letrozole, and gonadotropin) or had any history of autoimmune and genetic disease, or iatrogenic conditions (for example, radiation therapy or pelvic surgery), as these factors have been shown to alter the serum reproductive hormone and AMH levels. Patients were stratified into the following age groups: 21-29 years (Group 1), 30-34 years (Group 2), 35-39 years (Group 3) and 40-45 years (Group 4).

Measurement of reproductive hormones and $\mathrm{AMH}$

Blood samples were obtained by venipuncture at 7:30 A.M.-10:00 A.M., and the basal serum FSH, LH, estradiol (E2), total testosterone (TT) levels, and serum AMH levels were tested simultaneously on spontaneous cycle days 2-4 and prior to the beginning of IVF/ICSI cycles. The FSH, LH, E2, TT (kit from Abbott Ireland Diagnostics Division Lisnamuck, Longford Co. Longford Ireland) and AMH (kit from Roche Diagnostics $\mathrm{GmbH}$, Mannheim, Germany) levels were determined with commercial kits and an electrochemiluminescence immunoassay. 
The experienced and qualified sonographers performed ultrasonographic evaluations for all subjects during spontaneous cycle days 2-4 using a two-dimensional transvaginal probe of $9 \mathrm{MHz}$ frequency (HD11 XE, Philips Ultrasound, Inc., Bothell WA. USA). The total number of 2-9 mm antral follicles in both ovaries was measured and recorded. OV was calculated as the volume of an ellipsoid, that is, $0.52 \times$ Length $\times$ Width $\times$ Depth. The total basal volume of both ovaries was evaluated in each patient.

Calculation of body mass index (BMI), FSH/LH ratio and ovarian response prediction index (ORPI)

Height and weight were used to calculate BMI, that is, weight $(\mathrm{kg}) /$ height $\left(\mathrm{m}^{2}\right)$. Serum FSH and LH concentration were used to calculate $\mathrm{FSH} / \mathrm{LH}$ ratio. The ORPI was defined by the following equation: $\mathrm{ORPI}=(\mathrm{AMH} \times \mathrm{AFC}) /$ Patient age [9].

Ovarian stimulation protocols

The ovarian stimulation protocols performed the GnRH antagonist protocols. The gonadotropin (Gn) was recombinant FSH (Gonal-f, Laboratoires Serono SA, Aubonne, Switzerland) and human menopausal gonadotrophin for injection (Livzon Pharmaceutical Group Inc. Zhuhai, Guangdong Province, China). The antagonist was Ganirelix Injection (ORGALUTRAN, Ravensburg, Germany). After the third day of treatment, the $\mathrm{Gn}$ dose was adjusted to the patient response. The total $\mathrm{Gn}$ dose was $2076.72 \pm 963.33 \mathrm{IU}$, and the Gn treatment duration was $9.65 \pm 2.74$ days in each IVF/ICSI cycle. The trigger drug was recombinant human chorionic gonadotropin alpha for injection (OVIDREL $250 \mu \mathrm{g}$, Laboratoires Serono S.A. (LSA), Aubonne, Switzerland).

\section{Statistical analysis}

Microsoft Excel 2013 software (Microsoft Corporation, Redmond, State of Washington, USA) and SPSS 21.0 (IBM Corporation, New York, USA) were used for all statistical analysis. The data were presented as the mean \pm standard deviation (SD), as calculated for all subjects and each group. The one-way ANOVA test was used to assess the differences between the mean values of parameters in the different groups. Pearson's correlation analysis was used to assess the correlations between different parameters. Receiver Operating Characteristic Curve (ROC Curve) analysis was used to analyze the predictive accuracy of variables, and to calculate the area under the curve (AUC), and the cut-off values and corresponding sensitivity and specificity. Tests were considered statistically significant if $\mathrm{P} \otimes 0.05$.

Ethics and informed consent statement

This study, and the accompanying consent forms, were approved by the Ethics Committee and Institutional Review Board of Peking University International Hospital and Tangshan Maternity and Child Healthcare Hospital. Participants were enrolled in the study after written informed consent was obtained. 


\section{Results}

One-way ANOVA analysis between different subgroups

Clinical data and variable data of subjects presented in Table 1, and the boxplots of variables' frequency distribution presented in Fig. 1. According the diagnosis of patients, the rates of primary infertility type and secondary type were $37.04 \%$ and $62.96 \%$, respectively. The rates of male factor, female factor and double factor infertility were $7.41 \%, 25.93 \%$ and $66.66 \%$, respectively. 
Table 1

Frequencies of 319 subjects' clinical data and variable data

\begin{tabular}{|c|c|c|c|c|c|c|c|}
\hline \multirow[t]{4}{*}{ Variables } & \multicolumn{2}{|c|}{319 subjects } & \multicolumn{5}{|c|}{ Subgroups } \\
\hline & \multirow[t]{3}{*}{$\begin{array}{l}\text { Mean } \pm \\
\text { SD }\end{array}$} & \multirow[t]{3}{*}{$\begin{array}{l}5 \%- \\
95 \%\end{array}$} & \multirow{3}{*}{$\begin{array}{l}\text { Group } 1 \\
(n=36) \\
\text { Mean } \pm \\
\text { SD }\end{array}$} & \multirow{3}{*}{$\begin{array}{l}\text { Group } 2 \\
(n=29) \\
\text { Mean } \pm \\
\text { SD }\end{array}$} & \multirow{3}{*}{$\begin{array}{l}\text { Group } 3 \\
(n=164) \\
\text { Mean } \pm \\
\text { SD }\end{array}$} & \multirow{3}{*}{$\begin{array}{l}\text { Group } 4 \\
(n=90) \\
\text { Mean } \pm \\
\text { SD }\end{array}$} & \multirow[t]{3}{*}{$\begin{array}{l}\mathrm{P} \\
\text { value }\end{array}$} \\
\hline & & & & & & & \\
\hline & & & & & & & \\
\hline Age & $\begin{array}{l}36.92 \pm \\
4.91\end{array}$ & $\begin{array}{l}26.00- \\
44.00\end{array}$ & $\begin{array}{l}26.64 \pm \\
1.97\end{array}$ & $\begin{array}{l}32.07 \pm \\
1.53\end{array}$ & $\begin{array}{l}37.19 \pm \\
1.18\end{array}$ & $\begin{array}{l}42.06 \pm \\
1.72\end{array}$ & 0.000 \\
\hline $\begin{array}{l}\text { Duration of } \\
\text { infertility }\end{array}$ & $\begin{array}{l}4.82 \pm \\
3.77\end{array}$ & $\begin{array}{l}1.00- \\
14.00\end{array}$ & $\begin{array}{l}3.34 \pm \\
2.00\end{array}$ & $\begin{array}{l}4.59 \pm \\
2.58\end{array}$ & $\begin{array}{l}4.85 \pm \\
3.67\end{array}$ & $\begin{array}{l}5.63 \pm \\
4.76\end{array}$ & 0.034 \\
\hline BMI & $\begin{array}{l}23.31 \pm \\
3.13\end{array}$ & $\begin{array}{l}19.00- \\
29.26\end{array}$ & $\begin{array}{l}22.84 \pm \\
2.37\end{array}$ & $\begin{array}{l}23.06 \pm \\
4.17\end{array}$ & $\begin{array}{l}23.14 \pm \\
3.13\end{array}$ & $\begin{array}{l}23.92 \pm \\
2.97\end{array}$ & 0.228 \\
\hline AFC & $\begin{array}{l}13.37 \pm \\
7.31\end{array}$ & $\begin{array}{l}3.00- \\
25.40\end{array}$ & $\begin{array}{l}20.04 \pm \\
7.34\end{array}$ & $\begin{array}{l}18.23 \pm \\
7.46\end{array}$ & $\begin{array}{l}12.95 \pm \\
6.95\end{array}$ & $\begin{array}{l}9.78 \pm \\
4.99\end{array}$ & 0.000 \\
\hline $\begin{array}{l}\text { OV (total) } \\
(\mathrm{ml})\end{array}$ & $\begin{array}{l}6.74 \pm \\
2.57\end{array}$ & $\begin{array}{l}3.81- \\
11.58\end{array}$ & $\begin{array}{l}6.51 \pm \\
1.65\end{array}$ & $\begin{array}{l}6.46 \pm \\
2.54\end{array}$ & $\begin{array}{l}6.92 \pm \\
2.58\end{array}$ & $\begin{array}{l}6.57 \pm \\
2.87\end{array}$ & 0.716 \\
\hline $\begin{array}{l}\mathrm{AMH} \\
(\mathrm{ng} / \mathrm{ml})\end{array}$ & $\begin{array}{l}3.24 \pm \\
2.42\end{array}$ & $\begin{array}{l}0.55- \\
8.23\end{array}$ & $\begin{array}{l}3.97 \pm \\
2.25\end{array}$ & $\begin{array}{l}3.12 \pm \\
2.30\end{array}$ & $\begin{array}{l}3.44 \pm \\
2.62\end{array}$ & $\begin{array}{l}2.59 \pm \\
1.98\end{array}$ & 0.014 \\
\hline $\begin{array}{l}\text { FSH } \\
\text { (IU/liter) }\end{array}$ & $\begin{array}{l}7.09 \pm \\
3.99\end{array}$ & $\begin{array}{l}2.11- \\
12.97\end{array}$ & $\begin{array}{l}6.29 \pm \\
1.73\end{array}$ & $\begin{array}{l}7.08 \pm \\
5.47\end{array}$ & $\begin{array}{l}7.22 \pm \\
4.47\end{array}$ & $\begin{array}{l}7.22 \pm \\
3.10\end{array}$ & 0.666 \\
\hline LH (IU/liter) & $\begin{array}{l}4.28 \pm \\
3.12\end{array}$ & $\begin{array}{l}1.01- \\
10.47\end{array}$ & $\begin{array}{l}4.28 \pm \\
3.08\end{array}$ & $\begin{array}{l}3.92 \pm \\
2.68\end{array}$ & $\begin{array}{l}4.64 \pm \\
3.47\end{array}$ & $\begin{array}{l}3.78 \pm \\
2.58\end{array}$ & 0.240 \\
\hline E2 (pg/ml) & $\begin{array}{l}85.80 \pm \\
113.12\end{array}$ & $\begin{array}{l}15.75- \\
314.50\end{array}$ & $\begin{array}{l}83.20 \pm \\
116.91\end{array}$ & $\begin{array}{l}98.04 \pm \\
105.60\end{array}$ & $\begin{array}{l}80.43 \pm \\
100.34\end{array}$ & $\begin{array}{l}92.63 \pm \\
136.06\end{array}$ & 0.823 \\
\hline $\begin{array}{l}\text { TT } \\
\text { (nmol/liter) }\end{array}$ & $\begin{array}{l}0.53 \pm \\
0.81\end{array}$ & $\begin{array}{l}0.12- \\
0.94\end{array}$ & $\begin{array}{l}0.43 \pm \\
0.20\end{array}$ & $\begin{array}{l}0.42 \pm \\
0.19\end{array}$ & $\begin{array}{l}0.65 \pm \\
1.10\end{array}$ & $\begin{array}{l}0.41 \pm \\
0.18\end{array}$ & 0.437 \\
\hline ORPI & $\begin{array}{l}1.45 \pm \\
1.62\end{array}$ & $\begin{array}{l}0.11- \\
5.18\end{array}$ & $\begin{array}{l}3.15 \pm \\
2.18\end{array}$ & $\begin{array}{l}1.94 \pm \\
1.75\end{array}$ & $\begin{array}{l}1.39 \pm \\
1.51\end{array}$ & $\begin{array}{l}0.69 \pm \\
0.67\end{array}$ & 0.000 \\
\hline $\begin{array}{l}\mathrm{FSH} / \mathrm{LH} \\
\text { ratio }\end{array}$ & $\begin{array}{l}2.19 \pm \\
1.81\end{array}$ & $\begin{array}{l}0.59- \\
5.29\end{array}$ & $\begin{array}{l}2.23 \pm \\
1.90\end{array}$ & $\begin{array}{l}2.88 \pm \\
3.50\end{array}$ & $\begin{array}{l}1.97 \pm \\
1.49\end{array}$ & $\begin{array}{l}2.32 \pm \\
1.27\end{array}$ & 0.099 \\
\hline $\begin{array}{l}\text { Retrieved } \\
\text { oocytes }\end{array}$ & $\begin{array}{l}12.03 \pm \\
6.66\end{array}$ & $\begin{array}{l}5.00- \\
26.00\end{array}$ & $\begin{array}{l}13.64 \pm \\
6.77\end{array}$ & $\begin{array}{l}10.38 \pm \\
6.62\end{array}$ & $\begin{array}{l}13.02 \pm \\
7.01\end{array}$ & $\begin{array}{l}10.10 \pm \\
5.41\end{array}$ & 0.002 \\
\hline \multicolumn{8}{|c|}{ \#: The differences between the mean values of parameters in the four groups. } \\
\hline
\end{tabular}


$\mathrm{BMI}$, total volume of bilateral ovaries, serum $\mathrm{FSH}, \mathrm{LH}, \mathrm{E} 2, \mathrm{TT}$, and $\mathrm{FSH} / \mathrm{LH}$ ratio were not significantly different among the four subgroups; however, the duration of infertility, AFC, serum AMH levels, ORPI and retrieved oocyte numbers were significantly different among the four subgroups.

Multiple comparisons showed that the durations of infertility were significantly different between Group 1 and Groups 3 and $4(P=0.034, P=0.003)$. The AFC were significantly different between Group 1 and Groups 3 and $4(P=0.000, P=0.000)$, between Group 2 and Groups 3 and $4(P=0.001, P=0.000)$, and between Group 3 and Group $4(P=0.004)$. AFC decreased gradually as age increased, as presented in Fig. 1 (a). The AMH levels were significantly different between Group 1 and Group $4(P=0.004)$ and between Group 3 and Group $4(P=0.009)$. The AMH boxplot is presented in Fig. 1 (b). ORPI was significantly different between Group 1 and Groups 2,3 , and $4(P=0.005, P=0.000, P=0.000)$, between Group 2 and Group $4(P=0.001)$, and between Group 3 and Group $4(P=0.002)$. ORPI decreased gradually as age increased, as presented in Fig. 1 (d). The retrieved oocyte numbers were significantly different between Group 1 and Groups 2 and $4(P=0.046, P=0.006)$, between Group 2 and Group $3(P=$ $0.046)$, and between Group 3 and Group $4(P=0.001)$. The boxplot of retrieved oocyte numbers is presented in Fig. 1(f).

Pearson correlation analysis

AFC demonstrated positive correlation with the total volume of bilateral ovaries $(P=0.009), A M H(P=$ $0.000)$ and ORPI $(P=0.000)$; however, AFC was negatively correlated with age $(P=0.000)$ and serum FSH level $(P=0.000)$. The above-mentioned parameters could reflect ovarian reserve.

There were positive correlations between the retrieved oocyte numbers and AFC $(P=0.000)$, total volume of bilateral ovaries $(P=0.020), A M H(P=0.000)$, ORPI $(P=0.000)$, and LH $(P=0.011)$; however, a negative correlation existed between the retrieved oocyte numbers and age $(P=0.003)$. The above-mentioned parameters could reflect ovarian response.

There were negative correlations between age and AFC $(P=0.000), \operatorname{AMH}(P=0.018)$, ORPI $(P=0.000)$ and retrieved oocyte numbers $(P=0.003)$. BMI was inversely correlated with $F S H(P=0.015)$ and $F S H / L H$ ratio $(P=0.010)$ but did not correlate with AMH or AFC.

ROC Curve analysis for evaluating ovarian reserve

In general, $\mathrm{AFC}<5$ was one of the standards indicating decline of ovarian reserve [10]. Using the abovementioned standards and the ROC Curve to evaluate the significant variables of ovarian reserve decrease, which included age, total volume of bilateral ovary, FSH, and ORPI, the corresponding AUC was $0.707,0.629,0.652$, and 0.903 , respectively. Although the AUC of AMH was 0.613 , it was less valuable to access ovarian reserve $(P=0.065)$. AUC, cut-off values, sensitivity and specificity of variables evaluating ovarian reserve are presented in Table 2 and Fig. 2 (a)-(b). 
Table 2

The AUC and cut-off values of variables evaluating ovarian reserve and response

\begin{tabular}{|c|c|c|c|c|c|c|c|}
\hline \multicolumn{2}{|c|}{$\begin{array}{l}\text { Characteristics of ovarian } \\
\text { function }\end{array}$} & Variables & AUC & $\begin{array}{l}P \\
\text { value }\end{array}$ & $\begin{array}{l}\text { Cut-off } \\
\text { value }\end{array}$ & $\begin{array}{l}\text { Sensitivity } \\
\text { (\%) }\end{array}$ & $\begin{array}{l}\text { Specificity } \\
\text { (\%) }\end{array}$ \\
\hline \multirow{4}{*}{\multicolumn{2}{|c|}{ Ovarian reserve }} & OV & 0.629 & 0.043 & 5.54 & 68.3 & 60.9 \\
\hline & & ORPI & 0.903 & 0.000 & 0.245 & 90.1 & 73.9 \\
\hline & & Age & 0.707 & 0.002 & 36.50 & 88.0 & 40.8 \\
\hline & & $\mathrm{FSH}$ & 0.652 & 0.014 & 7.05 & 66.7 & 61.6 \\
\hline \multirow{8}{*}{$\begin{array}{l}\text { Ovarian } \\
\text { response }\end{array}$} & \multirow{6}{*}{$\begin{array}{l}\text { Excessive } \\
\text { response }\end{array}$} & AFC & 0.798 & 0.000 & 14.50 & 77.8 & 77.1 \\
\hline & & $\mathrm{AMH}$ & 0.750 & 0.000 & 3.955 & 59.7 & 79.1 \\
\hline & & ORPI & 0.833 & 0.000 & 0.886 & 84.7 & 67.3 \\
\hline & & Age & 0.626 & 0.002 & 40.50 & 27.0 & 94.6 \\
\hline & & FSH & 0.615 & 0.004 & 5.705 & 72.4 & 52.7 \\
\hline & & $\begin{array}{l}\mathrm{FSH} / \mathrm{LH} \\
\text { ratio }\end{array}$ & 0.618 & 0.003 & 1.753 & 56.2 & 67.6 \\
\hline & \multirow[t]{2}{*}{ Low response } & $\begin{array}{l}\mathrm{FSH} / \mathrm{LH} \\
\text { ratio }\end{array}$ & 0.786 & 0.047 & 2.983 & 75.0 & 83.8 \\
\hline & & $\mathrm{AMH}$ & 0.751 & 0.011 & 1.405 & 70.8 & 77.8 \\
\hline
\end{tabular}

According to our results, ovarian reserve would decrease when subjects' age and FSH were more than the cut-off values, moreover, the total volume of bilateral ovary and ORPI were less than the cut-off values.

ROC Curve analysis for forecasting ovarian response

According to the retrieved oocyte numbers, ovarian response categories were divided into low response (oocytes $\leq 3$ ), normal response (4-14 oocytes) and excessive response (oocytes $\geq 15)[9,10]$.

We used the abovementioned standards and the ROC Curve to forecast the significant variables of excessive ovarian response, which included age, AFC, AMH, ORPI, FSH and FSH/LH ratio, and to forecast the significant parameters of low ovarian response, which included AMH, FSH/LH ratio. The AUC, cut-off values, and corresponding sensitivity and specificity of variables evaluating ovarian response are presented in Table 2, Fig. 3 (a)-(b), and Fig. 4 (a)-(b).

\section{Discussion}


Ovarian reserve can be altered or reduced due to age, disease, pelvic operation, chemotherapy or radiotherapy, among other factors, and it is beneficial to create treatment regimes, survey treatment effects and forecast prognoses for infertile women by evaluating ovarian reserve or response. Our results indicated that the AFC, serum AMH levels, ORPI and retrieved oocyte numbers were significantly different among the four subgroups and that there were negative correlations between age and AFC, AMH, ORPI, retrieved oocyte numbers. Thus, we discovered that AFC and ORPI decreased gradually with age. Lee et al. [11] and Raeissi et al. [12] observed increased FSH levels and decreased AMH levels with increasing age in women. Bozkurt et al. [13] reported that AMH was inversely correlated with age; however, AFC revealed a stronger correlation with age in both the fertile and infertile populations compared with basal $\mathrm{FSH}$ and $\mathrm{AMH}$; the decrease in ovarian reserve in infertile patients was directly related to age, not infertility.

AFC on day 2-4 of the menstrual cycle, evaluated by transvaginal ultrasound, is commonly used to determine ovarian reserve, but AFC measurement is prone to error because of different sonographers. To explore the evaluative effectiveness of various variables, we analyzed the correlation of AFC with other variables and found that AFC showed a positive correlation with total volume of bilateral ovary, $\mathrm{AMH}$ and ORPI; however, AFC showed a negative correlation with age and serum FSH level. However, Somigliana et al. [14] insisted that low serum AMH is not associated with female subfertility.

The literature has reported that BMI is not associated with the AMH levels in the general population of infertile women or in patients without polycystic ovary syndrome (PCOS); however, BMI is significantly and inversely correlated with AMH in women with PCOS [15]. Another study found that age is negatively correlated with $\mathrm{AMH}$ and $\mathrm{AFC}$ across all races $(\mathrm{P}<0.05)$ and that elevated $\mathrm{BMI}$ is negatively correlated with $\mathrm{AMH}$ in Caucasian women but not in African-American, Hispanic, or Asian women [16]. The results from our research showed that BMI was inversely correlated with $\mathrm{FSH}$ and $\mathrm{FSH} / \mathrm{LH}$ ratio but did not correlate with $\mathrm{AMH}$ or AFC. In brief, debate still exists regarding the influence of BMI on ovarian function and $\mathrm{AMH}$ levels.

The ROC analysis results in our study revealed that the significant variables for evaluating ovarian reserve decrease included age, total volume of bilateral ovary, FSH, and ORPI. Moreover, the AUC of ORPI was higher than those of the other three variables, and the diagnostic accuracy reached a "high" grade; the cut-off value of ORPI from ROC analysis was 0.245 (sensitivity $90.1 \%$, specificity $73.9 \%$ ).

Assessments of the AMH and FSH levels in combination with female age could be helpful in predicting ovarian reserve in infertile women [12].

Many studies [17-21] have discussed how AFC and AMH could be used to assess ovarian reserve. However, our research did not find that these two variables acted as a single variable to significantly assess ovarian function. Serum AMH and AFC begin to decline in women between 34 and 35 years old, and AMH predicts biological age earlier than FSH or AFC do, and AFC does so earlier than FSH does [17]. By age 32 , over $50 \%$ of women with subfertility had AMH levels categorized as "low fertility" (AMH $\leq$ $19.5 \mathrm{pmol} /$ liter), a figure that increased to $75 \%$ by age 39 , with a decrease in mean $\mathrm{AMH}$ of 
$1.72 \mathrm{pmol} /$ liter/year [18]. The serum AMH cut-off value for the normal ovarian reserve was calculated as $0.37 \mathrm{ng} / \mathrm{ml}$ (sensitivity $71.43 \%$, specificity $66.67 \%$, positive prediction $83.33 \%$, negative prediction $50 \%$ ) [19]. AMH should be considered a more reliable ovarian reserve assessment test compared to FSH because there was a strong positive correlation between the serum AMH level and AFC; further, the use of AMH combined with AFC may improve ovarian reserve evaluation [20]. The present findings suggest the applicability of $\mathrm{AMH}$ determination as a marker for actual fertility in subfertile women with elevated basal FSH levels, as AMH was significantly associated with the timing of reproductive stages (i.e., the occurrence of menopausal transition or menopause during follow-up) [21]. Our results showed that the cut-off value of age was 36.50 for predicting ovarian reserve decline and that the corresponding sensitivity and specificity were $88.0 \%$ and $40.8 \%$, respectively.

We found that the significant variables forecasting excessive ovarian response included age, AFC, AMH, $\mathrm{ORPI}, \mathrm{FSH}$ and $\mathrm{FSH} / \mathrm{LH}$ ratio, and that the significant variables forecasting low ovarian response included $\mathrm{AMH}$ and $\mathrm{FSH} / \mathrm{LH}$ ratio. Interestingly, ORPI and $\mathrm{FSH} / \mathrm{LH}$ ratio demonstrated better effectiveness in evaluating ovarian response. When used to predict excessive response, the cut-off value of ORPI from ROC analysis was 0.886 (sensitivity $84.7 \%$, specificity $67.3 \%$ ), and the cut-off value of FSH/LH ratio was 1.753 (sensitivity $56.2 \%$, specificity $67.6 \%$ ). When used to predict low response, the cut-off value of $\mathrm{FSH} / \mathrm{LH}$ ratio was 2.983 (sensitivity $75.0 \%$, specificity $83.8 \%$ ).

In recent years, many studies have focused on the value of a single parameter. For example, AMH was strongly associated with oocyte yield after ovarian stimulation and may therefore predicted ovarian response and the quality of oocytes and embryos $[2,19,22]$, and AMH had a higher predictive value for the responders and $\mathrm{AFC}$ than for $\mathrm{FSH}, \mathrm{E} 2$ and chronological age, moreover, could predict the risk of ovarian hyperstimulation syndrome (OHSS) among patients [23, 24]. Vembu et al. [25] reported ROC curve was plotted to predict the hyper response (OHSS), which showed a serum AMH cut-off value of $6.85 \mathrm{ng} / \mathrm{ml}$ with a sensitivity of $66.7 \%$ and a specificity of $68.7 \%$ for PCOS group and $4.85 \mathrm{ng} / \mathrm{ml}$ with a sensitivity of $85.7 \%$ and a specificity of $89.7 \%$ in non-PCOS group. AFC is superior to AMH in predicting poor ovarian response. The cut-off point for mean AMH and AFC in discriminating between poor and normal ovarian response cycles was $0.94 \mathrm{ng} / \mathrm{ml}$ (with a sensitivity of $70 \%$ and a specificity of $86 \%$ ) and 5.5 (with a sensitivity of $91 \%$ and a specificity of $91 \%$ ), respectively [26]. Iranian women with a basal AMH level $>6.95 \mathrm{ng} / \mathrm{ml}$ are at a high risk of developing OHSS, and those with AMH level $<1.65 \mathrm{ng} / \mathrm{ml}$ are poor responders [27]. Our results showed that the AMH cut-off value for excessive ovarian response and low response was $3.955 \mathrm{ng} / \mathrm{ml}$ (sensitivity $59.7 \%$, specificity $79.1 \%$ ) and $1.405 \mathrm{ng} / \mathrm{ml}$ (sensitivity $70.8 \%$, specificity $77.8 \%$ ), AFC cut-off value for excessive ovarian response was 14.50 (sensitivity $77.8 \%$, specificity $77.1 \%)$, respectively.

Currently, two popular combined indexes, ORPI and FSH/LH ratio, are used to assess ovarian function. Regarding the probability of collecting greater than or equal to 4 oocytes, ORPI showed an AUC of 0.91 and an efficacy of $88 \%$ at a cut-off of 0.2 , but for the probability of collecting greater than or equal to 15 oocytes, ORPI showed an AUC of 0.89 and an efficacy of $82 \%$ at a cut-off of 0.9 [9]. The cut-off value reported by that study approximated our results. Oliveira et al. [28] reported the ORPI offered excellent 
ovarian response prediction (AUC $=0.91)$, and good predictions for the possibility of collecting $>4 \mathrm{MII}$ oocytes $(A U C=0.84)$ and excessive ovarian response $(A U C=0.89)$ in infertile women, and ORPI value $(\geq$ 1.7) was the benchmark that indicated high risk for OHSS. Selcuk et al.[29] found that the level of association between the ovarian response tests and poor ovarian response data was (in descending order): ovarian sensitivity index (OSI), ORPI, $A F C, A M H$, and age ( $A U C=0.976,0.905,0.899,0.864,0.617$, respectively), and OSI and ORPI could be superior to other ovarian responsiveness markers for poor and high ovarian responses on cycles with agonist or antagonist protocols. However, ORPI was more convenient than OSI, because OSI could be calculated after informed of the number of retrieved oocytes. In addition, opposing views on ORPI effectiveness continue to exist. Another study showed that both $\mathrm{AMH}$ and $\mathrm{AFC}$ were good predictors of ovarian response with an $\mathrm{AUC}>0.75$ but that combining these variables was necessary as ORPI would not improve the prediction value [30]. Using the cut-off value derived from ROC analysis, cycles with an $\mathrm{FSH} / \mathrm{LH}$ ratio > or $=3$ produced fewer mature oocytes (8.25 vs. 11.74 ) and a higher percentage of poor ovarian response cycles ( $32.5 \%$ vs. $14.3 \%$ ). Additionally, the serum $\mathrm{FSH}$ level and $\mathrm{FSH} / \mathrm{LH}$ ratio at the commencement of gonadotropin stimulation were inversely correlated to the number of mature oocytes [6]. According to our results and previous reports in the literature, the abovementioned combined indexes had excellent performances in evaluating ovarian reserve and response.

Some shortcomings still exist in our research. First, there were no comparison data on ovarian function between fertile and infertile women. Second, we did not focus on predicting the influence of stimulation protocols and cycle cancellations. Previous research has shown that an elevated FSH/LH ratio $>3$ is more likely to result in the cancellation of the individual's cycle $(15 \%$ vs $5.24 \%, p=0.0001)$ and that the total gonadotropin dosage was greater in the higher-ratio group than in lower-ratio group (2636 vs $2242 \mathrm{IU}$; significant) [31]. Finally, we did not collect data on embryo quality and pregnancy outcome associated with parameters in this research. Several studies have paid close attention to treatment outcomes. An FSH/LH ratio less than 1.26 is associated with good oocyte parameters, high-quality embryos and implantation after ICSI [32].

\section{Conclusion}

Comparing the effectiveness of evaluating ovarian reserve and predicting ovarian response on age, ovarian volume, $\mathrm{AFC}$, serum FSH, AMH, FSH/LH ratio and ORPI, we found that ORPI was superior to the other parameters in evaluating ovarian reserve and predicting excessive ovarian response, whereas $\mathrm{FSH} / \mathrm{LH}$ ratio was superior to the other parameters in predicting low ovarian response. Consequently, we agreed that the evaluative effectiveness of a combined index exceeded that of a single parameter for evaluating the ovarian reserve and response of infertile women.

\section{Abbreviations}

AFC 
antral follicle count; AMH:anti-Müllerian hormone; AUC:the area under the curve; BMI:body mass index; E2:estradiol; FSH:follicle-stimulating hormone; GnRH:gonadotropin-releasing hormone; IVF/ICSI:in vitro fertilization/ intracytoplasmic sperm injection; LH:luteinizing hormone; OHSS:ovarian hyperstimulation syndrome; ORPI:ovarian response prediction index; OSI:ovarian sensitivity index; OV:ovary volume; PCOS:polycystic ovary syndrome; ROC Curve:Receiver Operating Characteristic Curve; SD:standard deviation; TT:total testosterone.

\section{Declarations}

Conflicts of interest

The authors have no conflicts of interest relevant to this article.

Funding

This work was financed and supported by the Peking University International Hospital Research Funds (YN2016QN06), which role was support in the design of the study, measurement of reproductive hormones and $\mathrm{AMH}$, collection, and analysis of data.

Author Contribution

Conceptualization: Zhou SJ. Data curation: Zhou SJ, Zhao MJ. Formal analysis: Zhou SJ, Zhao MJ. Investigation \& Measurement: Zhou SJ, Zhao MJ, Li C, Su X. Methodology \& Supervision: Zhou SJ. Writing-original draft: Zhou SJ, Zhao MJ. Writing-review \& editing: Zhou SJ.

Acknowledgments

The authors wish to thank all participants and their families for participating in this study. We gratefully acknowledge the help of Dr. Ming-Jia Zhao, Dr. Cui Li and Dr. Xing Su for the collection of data from Tangshan Maternity and Child Healthcare Hospital. And we gratefully acknowledge the help of Dr. Dian He for the statistical analysis, Dr. He was from Department of Epidemiology and Health Statistics, School of Public Health, Capital Medical University, Beijing, China. We also thank Nature Research Editing Service from Springer Nature (http://www.springernature.com) for editing this manuscript.

\section{References}

1.

Tobler KJ, Shoham G, Christianson MS, Zhao Y, Leong M, Shoham Z. Use of anti-mullerian hormone for testing ovarian reserve: a survey of 796 infertility clinics worldwide. J Assist Reprod Genet. 2015;32:1441-8.

2.

Peluso C, Fonseca FL, Rodart IF, Cavalcanti V, Gastaldo G, Christofolini DM, et al. AMH: An ovarian reserve biomarker in assisted reproduction. Clin Chim Acta. 2014;437:175-82.

3.

Sahmay S, Oncul M, Tuten A, Tok A, Acıkgoz AS, Cepni I. Anti-müllerian hormone levels as a predictor of the pregnancy rate in women of advanced reproductive age. J Assist Reprod Genet. 2014;31:1469-74. 4. 
Brodin T, Hadziosmanovic N, Berglund L, Olovsson M, Holte J. Comparing four ovarian reserve markersassociations with ovarian response and live births after assisted reproduction. Acta Obstet Gynecol Scand. 2015;94:1056-63.

5 .

Hvidman HW, Bentzen JG, Thuesen LL, Lauritsen MP, Forman JL, Loft A, et al. Infertile women below the age of 40 have similar anti-Müllerian hormone levels and antral follicle count compared with women of the same age with no history of infertility. Hum Reprod. 2016;31:1034-45.

6.

Ho JY, Guu HF, Yi YC, Chen MJ, Ho ES. The serum follicle-stimulating hormone-to-luteinizing hormone ratio at the start of stimulation with gonadotropins after pituitary down-regulation is inversely correlated with a mature oocyte yield and can predict "low responders". Fertil Steril. 2005;83:883-8.

7.

Prasad S, Gupta T, Divya A. Correlation of the Day 3 FSH/LH Ratio and LH Concentration in Predicting IVF Outcome. J Reprod Infertil. 2013;14:23-8.

8.

Seckin B, Turkcapar F, Ozaksit G. Elevated day 3 FSH/LH ratio: a marker to predict IVF outcome in young and older women. J Assist Reprod Genet. 2012;29:231-6.

9 .

Oliveira JB, Baruffi RL, Petersen CG, Mauri AL, Nascimento AM, Vagnini L, et al. A new ovarian response prediction index (ORPI): implications for individualised controlled ovarian stimulation. Reprod Biol Endocrinol. 2012;10:94.

10.

Ferraretti AP, La Marca A, Fauser BC, Tarlatzis B, Nargund G, Gianaroli L, et al. ESHRE consensus on the definition of 'poor response' to ovarian stimulation for in vitro fertilization: the Bologna criteria. Hum Reprod. 2011;26:1616-24.

11.

Lee JY, Jee BC, Lee JR, Kim CH, Park T, Yeon BR, et al. Age-related distributions of anti-Müllerian hormone level and anti-Müllerian hormone models. Acta Obstet Gynecol Scand. 2012;91:970-5.

12.

Raeissi A, Torki A, Moradi A, Mousavipoor SM, Pirani MD. Age-specific serum anti-mullerian hormone and follicle stimulating hormone concentrations in infertile Iranian women. Int J Fertil Steril. 2015;9:27-32. 13.

Bozkurt B, Erdem M, Mutlu MF, Erdem A, Guler I, Mutlu I, et al. Comparison of age-related changes in antiMüllerian hormone levels and other ovarian reserve tests between healthy fertile and infertile population. Hum Fertil (Camb). 2016;19:192-8.

14.

Somigliana E, Lattuada D, Colciaghi B, Filippi F, La Vecchia I, Tirelli A, et al. Serum anti-Müllerian hormone in subfertile women. Acta Obstet Gynecol Scand. 2015;94:1307-12.

15. 
Kriseman M, Mills C, Kovanci E, Sangi-Haghpeykar H, Gibbons W. Antimullerian hormone levels are inversely associated with body mass index (BMI) in women with polycystic ovary syndrome. J Assist Reprod Genet. 2015;32:1313-6.

16.

Moy V, Jindal S, Lieman H, Buyuk E. Obesity adversely affects serum anti-müllerian hormone (AMH) levels in Caucasian women. J Assist Reprod Genet. 2015;32:1305-11.

17.

Wiweko B, Prawesti DM, Hestiantoro A, Sumapraja K, Natadisastra M, Baziad A. Chronological age vs biological age: an age-related normogram for antral follicle count, FSH and anti-Mullerian hormone. J Assist Reprod Genet. 2013;30:1563-7.

18.

Naasan MN, Harrity C, Pentony L, Mocanu E. Anti-Mullerian hormone normogram in an Irish subfertile population. Ir J Med Sci. 2015;184:213-8.

19.

Celik E, Bastu E, Dural O, Yasa C, Buyru F. Relevance of anti-Müllerian hormone on in vitro fertilization outcome. Clin Exp Obstet Gynecol. 2013;40:66-9.

20.

Barbakadze L, Kristesashvili J, Khonelidze N, Tsagareishvili G. The correlations of anti-mullerian hormone, follicle-stimulating hormone and antral follicle count in different age groups of infertile women. Int J Fertil Steril. 2015;8:393-8.

21.

Yarde F, Voorhuis M, Dólleman M, Knauff EA, Eijkemans MJ, Broekmans FJ. Antimüllerian hormone as predictor of reproductive outcome in subfertile women with elevated basal follicle-stimulating hormone levels: a follow-up study. Fertil Steril. 2013;100:831-8.

22.

Xu H, Zeng L, Yang R, Feng Y, Li R, Qiao J. Retrospective cohort study: AMH is the best ovarian reserve markers in predicting ovarian response but has unfavorable value in predicting clinical pregnancy in GnRH antagonist protocol. Arch Gynecol Obstet. 2017;295:763-70.

23.

Asada Y, Morimoto Y, Nakaoka Y, Yamasaki T, Suehiro Y, Sugimoto H, et al. Age-specific serum antiMüllerian hormone concentration in Japanese women and its usefulness as a predictor of the ovarian response. Reprod Med Biol. 2017;16:364-73.

24.

Jamil Z, Fatima SS, Cheema Z, Baig S, Choudhary RA. Assessment of ovarian reserve: Anti-Mullerian hormone versus follicle stimulating hormone. J Res Med Sci. 2016;21:100.

25 .

Vembu R, Reddy NS. Serum AMH Level to Predict the Hyper Response in Women with PCOS and NonPCOS Undergoing Controlled Ovarian Stimulation in ART. J Hum Reprod Sci. 2017;10:91-4. 26. 
Mutlu MF, Erdem M, Erdem A, Yildiz S, Mutlu I, Arisoy O, et al. Antral follicle count determines poor ovarian response better than anti-Müllerian hormone but age is the only predictor for live birth in in vitro fertilization cycles. J Assist Reprod Genet. 2013;30:657-65.

27.

Aghssa MM, Tarafdari AM, Tehraninejad ES, Ezzati M, Bagheri M, Panahi Z, et al. Optimal cutoff value of basal anti-mullerian hormone in iranian infertile women for prediction of ovarian hyper-stimulation syndrome and poor response to stimulation. Reprod Health. 2015;12:85.

28.

Oliveira JB, Franco JG Jr. The ovarian response prediction index (ORPI) as a clinical internal quality control to prevent ovarian hyperstimualtion syndrome. JBRA Assist Reprod. 2016;20:91-2.

29.

Selcuk S, Bilgic BE, Kilicci C, Kucukbas M, Cam C, Kutlu HT, et al. Comparison of ovarian responsiveness tests with outcome of assisted reproductive technology - a retrospective analysis. Arch Med Sci. 2018;14:851-9.

30.

Ashrafi M, Hemat M, Arabipoor A, Salman Yazdi R, Bahman-Abadi A, Cheraghi R. Predictive values of antimüllerian hormone, antral follicle count and ovarian response prediction index (ORPI) for assisted reproductive technology outcomes. J Obstet Gynaecol. 2017;37:82-8.

31.

Kofinas JD, Elias RT. Follicle-stimulating hormone/luteinizing hormone ratio as an independent predictor of response to controlled ovarian stimulation. Womens Health (Lond). 2014;10:505-9.

32.

Rehman R, Syed H, lqbal NT, Arif S, Sheharyar S. FSH/LH ratio in females and intracytoplasmic sperm injection. J Pak Med Assoc. 2015;65:1330-3.

\section{Figures}




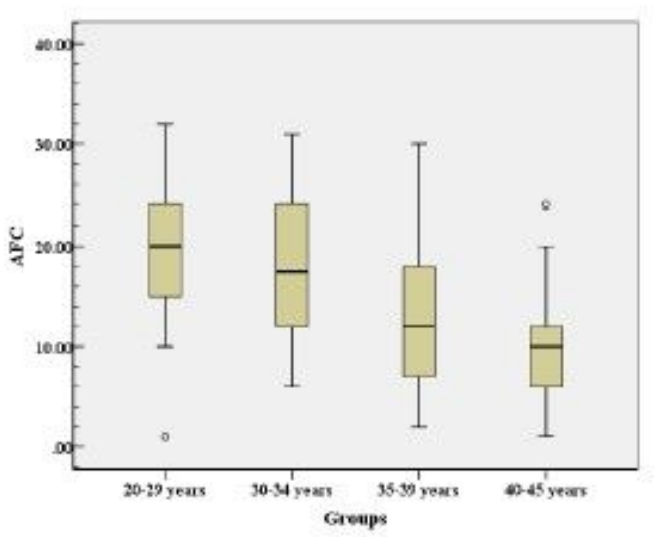

(a) The boxplot of AFC

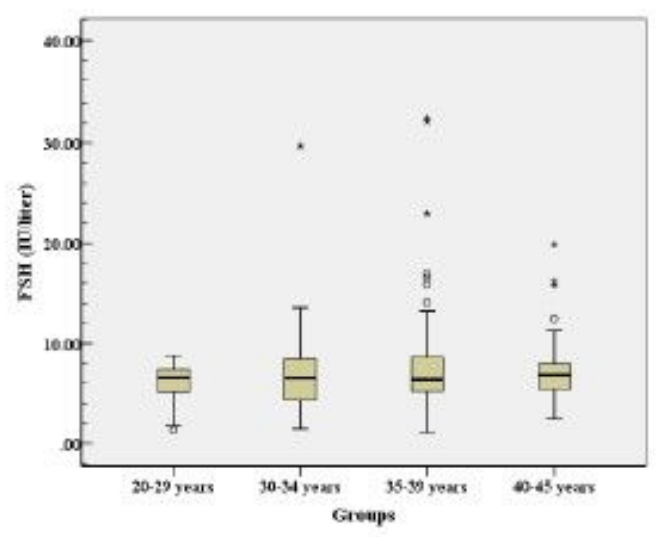

(c) The boxplot of FSH

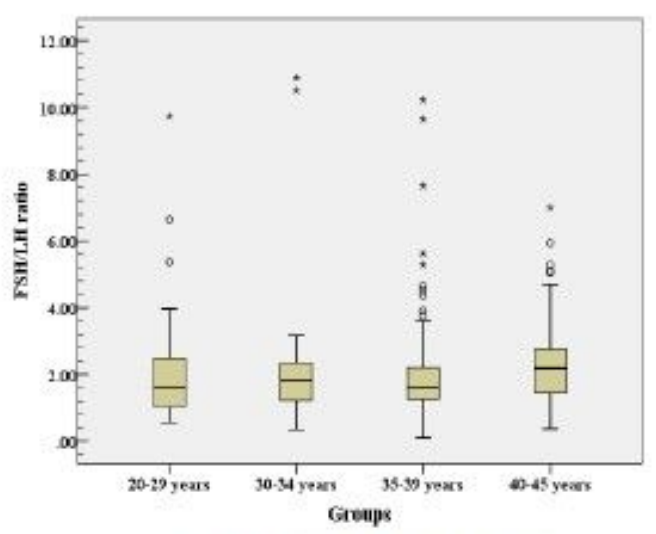

(e) The boxplot of $\mathrm{FSH} / \mathrm{LH}$ ratio

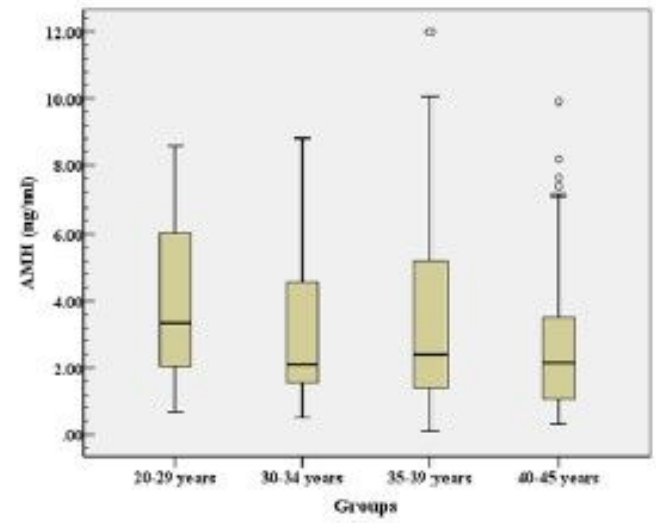

(b) The boxplot of AMH

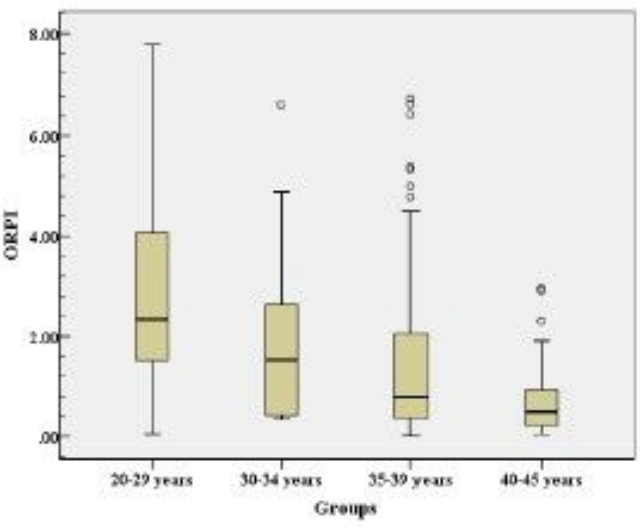

(d) The boxplot of ORPI

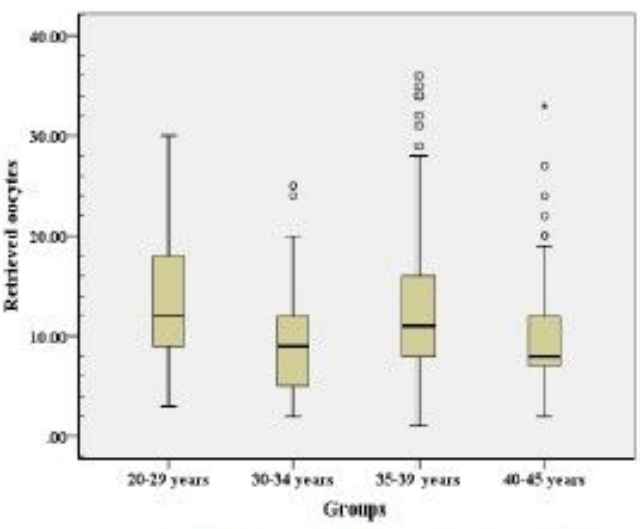

(f) The boxplot of retrieved oocytes

\section{Figure 1}

The boxplots of variables' frequency distribution. AFC: antral follicle count; $\mathrm{AMH}$ : anti-Müllerian hormone; FSH: follicle-stimulating hormone; ORPI: ovarian response prediction index; LH: luteinizing hormone. 


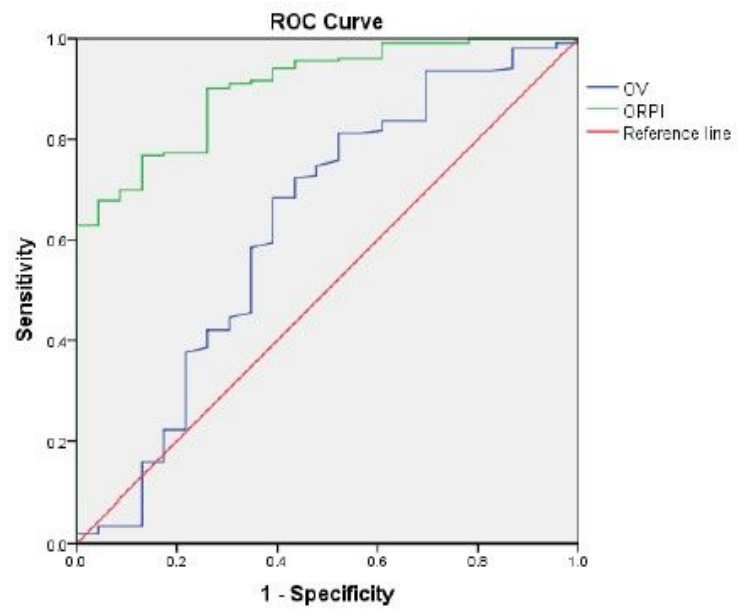

(a) ROC Curve of OV and ORPI evaluating ovarian reserve decrease

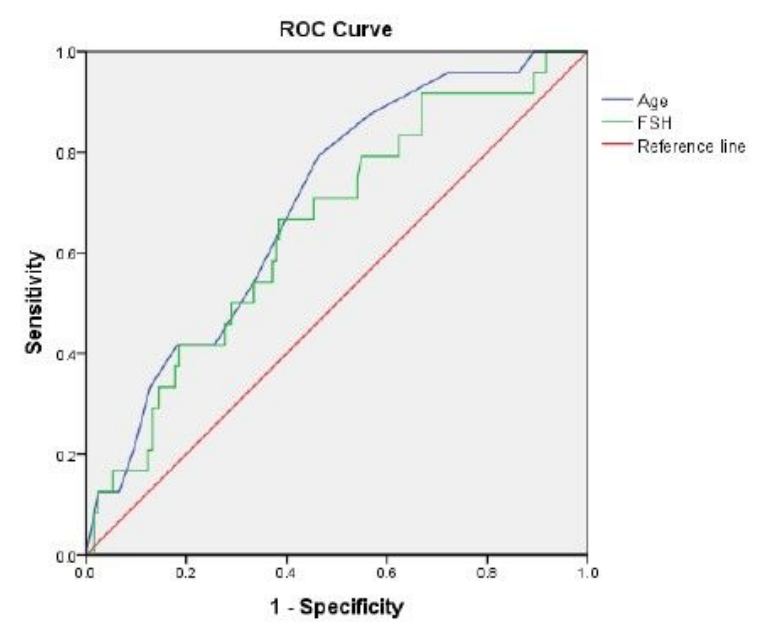

(b) ROC Curve of age and FSH evaluating ovarian reserve decrease

\section{Figure 2}

ROC Curve of variables evaluating ovarian reserve decrease. ROC Curve: Receiver Operating Characteristic Curve; FSH: follicle-stimulating hormone; OV: total volume of bilateral ovaries; ORPI: ovarian response prediction index. 


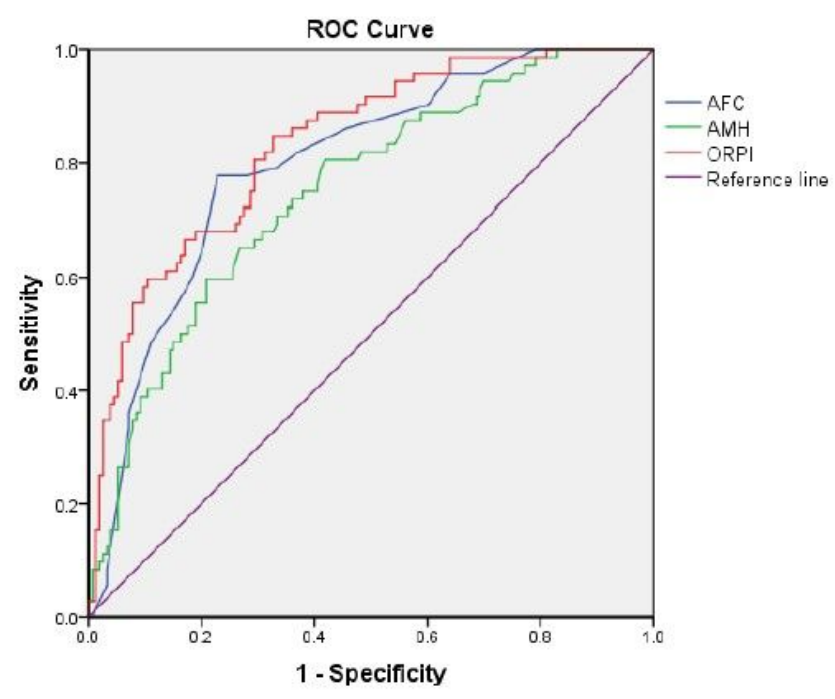

(a) ROC Curve of AFC, AMH and ORPI forecasting excessive ovarian response

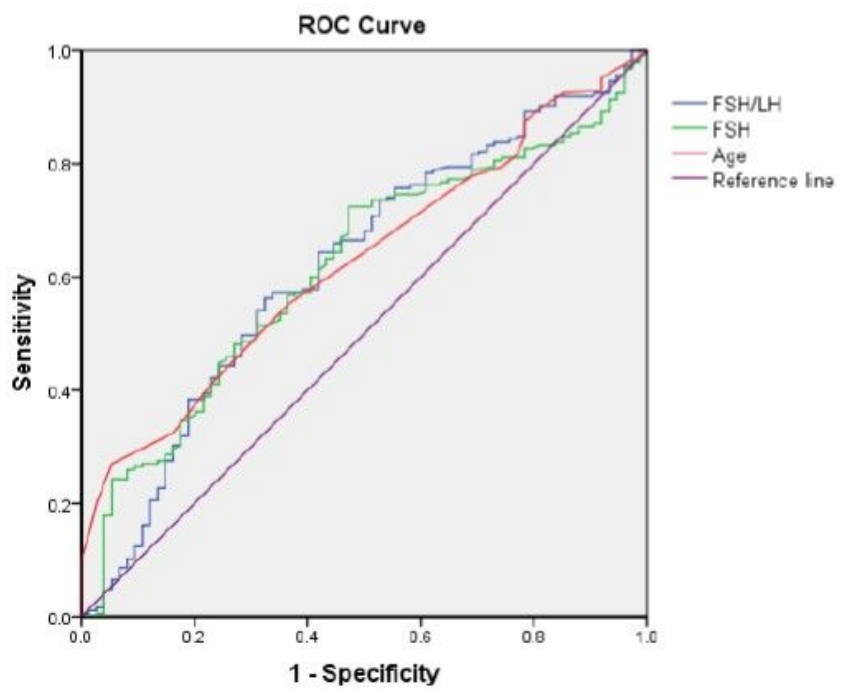

(b) ROC Curve of Age, FSH and FSH/LH ratio forecasting excessive ovarian response

\section{Figure 3}

ROC Curve of variables forecasting excessive ovarian response. ROC Curve: Receiver Operating Characteristic Curve; AFC: antral follicle count; AMH: anti-Müllerian hormone; ORPI: ovarian response prediction index; FSH: follicle-stimulating hormone; LH: luteinizing hormone. 


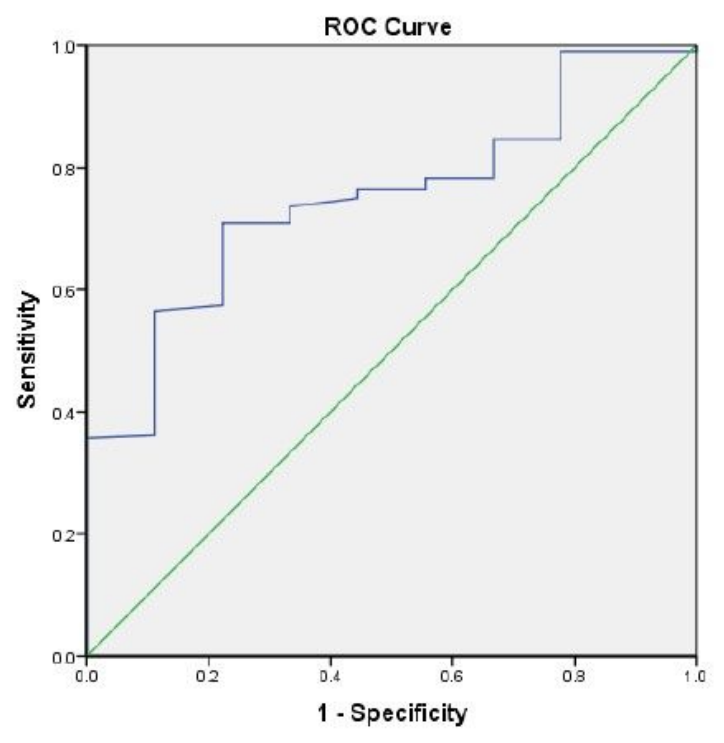

(a) ROC Curve of $\mathrm{AMH}$ forecasting low ovarian response

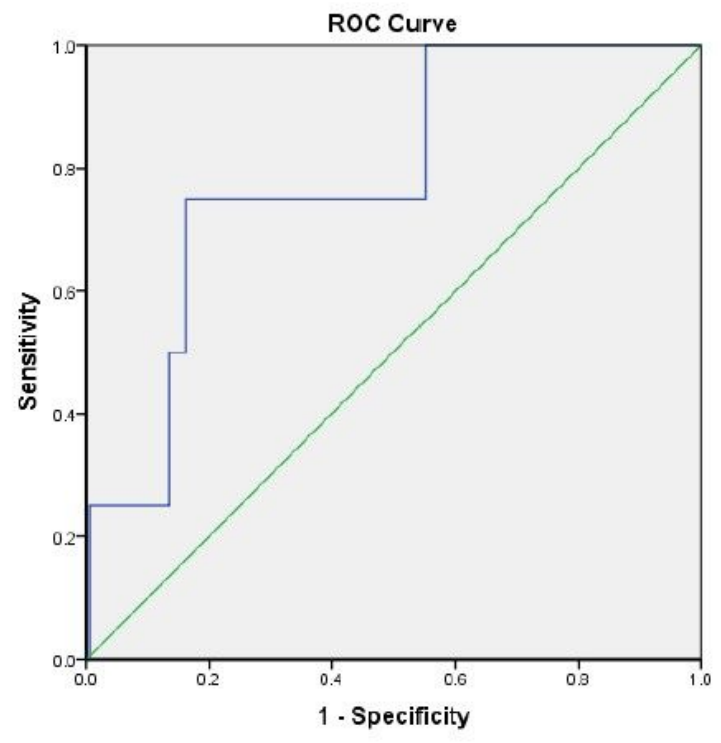

(b) ROC Curve of FSH/LH ratio forecasting low ovarian response

\section{Figure 4}

ROC Curve of variables forecasting low ovarian response. ROC Curve: Receiver Operating Characteristic Curve; AMH: anti-Müllerian hormone; FSH: follicle-stimulating hormone; LH: luteinizing hormone. 